\title{
Uma análise do setor externo brasileiro entre 2000 e 2012 a luz do debate sobre a desindustrialização
}

Welinton Conte Ferreira*

\begin{abstract}
Resumo: Este artigo pretende fazer uma análise da situação do setor externo brasileiro dentro do debate sobre o processo de desindustrialização da economia brasileira, apresentando toda a mudança qualitativa que vem ocorrendo neste setor nos últimos anos. $\mathrm{O}$ trabalho analisa tanto a evolução da participação dos produtos manufaturados, semimanufaturados e básicos nas exportações brasileiras quanto a mudança ocorrida na participação dos setores industriais, por intensidade tecnológica, nas exportações e nas importações brasileiras. O resultado do estudo indica estar ocorrendo no Brasil, no mínimo, um processo de reprimarização das exportações.
\end{abstract}

Palavras-Chave: Desindustrialização. Economia Brasileira. Reprimarização.

\section{An analysis of the Brazilian external sector between 2000 and 2012 in the light of the debate on deindustrialization}

Abstract: This article intends to analyze the situation of the Brazilian external sector within the debate about the deindustrialization process of the Brazilian economy, with all the qualitative change that has taken place in this sector in recent years. The paper analyzes both the evolution of the share of manufactured, semi-manufactured goods and commodities in Brazilian exports and the change in the share of industrial sectors, by technological intensity, in the Brazilian exports and imports. The result of the study indicates that it is occurring in Brazil, at least, a process of reprimarization export.

Keywords: Deindustrialization. Brazilian Economy. Reprimarization.

Classificação JEL: O10; O14; L60.

\section{Introdução}

Temos observado nos últimos anos um intenso debate entre os economistas sobre a existência ou não do processo de desindustrialização no Brasil. Enquanto alguns economistas afirmam que a abertura financeira e comercial juntamente com o câmbio valorizado (ambos reflexo da política econômica adotada desde a década de 90) desencadeou um processo de desindustrialização na economia brasileira ${ }^{1}$, outros economistas afirmam que as reformas econômicas implementadas pelo governo brasileiro na década de 90 foram benéficas ao setor

\footnotetext{
*Docente na Universidade Federal Fluminense (UFF). Departamento de Economia. Área: Microeconomia. Email: welintonconte87@gmail.com.

${ }^{1}$ Segundo Belluzzo e Almeida (2002), o regime cambial e monetário do Plano Real causou o rompimento de cadeias produtivas em vários setores industriais, reduzindo assim o valor agregado para um mesmo valor bruto da produção e, consequentemente, o nível de renda e emprego do setor. Além disso, segundo os autores, o arranjo entre câmbio e juros afetou o nível de investimento nos setores de bens transacionáveis.
} 
industrial brasileiro, pois facilitaram a importação de máquinas e equipamentos mais avançados, permitindo assim uma modernização do parque industrial brasileiro.

Todavia, independentemente da posição assumida por cada economista dentro do debate sobre a desindustrialização, acredito que todos devem estar preocupados com a transformação qualitativa que vem ocorrendo com o setor externo brasileiro, principalmente com relação aos setores industriais mais sofisticados. O fato de o Brasil apresentar déficits históricos nas contas de renda e serviços do balanço de pagamentos torna necessário que o país mantenha a balança comercial superavitária para que não dependa da conta de capital e da conta financeira para equilibrar seu balanço de pagamentos. Dessa forma, para evitar restrições no balanço de pagamentos, fato que historicamente se repete na economia brasileira, é necessário que o país apresente um setor exportador dinâmico, intensivo em tecnologia, ou seja, um setor externo predominantemente composto por manufaturas, uma vez que a elasticidade renda das importações de manufaturas é maior do que a elasticidade renda das importações de bens básicos (como as commodities). No entanto, para que este desejo seja alcançado é necessário que o governo adote políticas, tanto a nível macroeconômico quanto a nível microeconômico, que estejam de acordo com este objetivo.

Isso posto, esse artigo tem por objetivo fazer uma análise da situação do setor externo brasileiro dentro do debate sobre a desindustrialização (ou não) da economia brasileira, apresentando toda a mudança qualitativa que vem ocorrendo neste setor nos últimos anos. Para alcançar esse objetivo, o trabalho está dividido em seis seções, incluindo a presente introdução e a conclusão. Inicialmente na seção 2, iremos fazer uma abordagem teórica sobre o processo de desindustrialização, passando por conceitos de doença holandesa e da hipótese da inserção regressiva. Na seção 3 iremos apresentar e analisar alguns dados referentes ao setor industrial brasileiro, inserindo essa análise dentro do debate sobre o processo de desindustrialização. Em seguida, na seção 4, iremos exibir a evolução ocorrida nos últimos anos na composição das exportações brasileiras por fator agregado, analisando as possíveis causas dessa variação. Na seção 5 analisaremos mais especificamente a participação dos setores industriais, por intensidade tecnológica, no setor externo brasileiro. Por fim, o trabalho apresentará na sua última seção as conclusões. 


\section{Abordagem teórica: os conceitos de desindustrialização, doença holandesa e a hipótese da inserção regressiva}

Rowthorn e Ramaswany (1999) definiram desindustrialização como sendo uma redução persistente da participação do emprego industrial no emprego total de um país ou região. Um conceito mais amplo foi apresentado por Tregenna (2009), onde desindustrialização consiste em um processo de perda de participação do emprego industrial e do valor adicionado da indústria como proporção, respectivamente, do emprego total e do PIB.

O termo desindustrialização pode apresentar tanto uma conotação positiva quanto negativa. A conotação negativa está relacionada à destruição da indústria nacional como consequência da utilização de políticas macroeconômicas indevidas para o desenvolvimento produtivo. Já conotação positiva vem do fato de que a desindustrialização pode ser um processo normal que ocorre quando um país apresenta um desenvolvimento econômico bem sucedido, geralmente associado a melhorias no padrão de vida da população. Neste processo ocorre uma mudança no setor produtivo nacional, onde em um primeiro momento se tem uma diminuição da participação da agropecuária e um aumento da participação da indústria no produto interno bruto (PIB) e, em um momento seguinte, ocorre um aumento do peso do setor de serviços e uma diminuição do peso do setor industrial no PIB.

Com relação ao setor externo, uma importante observação é que a desindustrialização não está necessariamente relacionada a um processo de reprimarização da pauta de exportação. Caso a participação da indústria no emprego e no valor adicionado se reduza, relativamente aos outros setores, em função da transferência para o exterior das atividades industriais com menor valor agregado ou mais intensivas em mão de obra, a desindustrialização pode levar a um aumento da participação de produtos de maior intensidade tecnológica e maior valor adicionado na pauta de exportação. Porém, se a desindustrialização estiver associada a um processo de reprimarização da pauta de exportação, ou seja, a uma especialização nas exportações de produtos básicos e manufaturados de baixa intensidade tecnológica e baixo valor agregado, então poderá estar ocorrendo a chamada “doença holandesa" (BRESSER-PEREIRA, 2008).

Com o que foi dito acima podemos concluir que doença holandesa e desindustrialização são conceitos que podem ou não ser correspondentes. Enquanto a desindustrialização pode ocorrer simplesmente em função do processo de desenvolvimento econômico, o surgimento da doença holandesa acarreta necessariamente o surgimento da 
desindustrialização. Ademais, o processo de desindustrialização, ao contrário da doença holandesa, não necessariamente acarretará o processo de reprimarização da pauta de exportação.

A doença holandesa é um fenômeno que ocorre em função da existência de recursos naturais abundantes que geram vantagens comparativas ricardianas ao país que os possui e, de acordo com os mecanismos de mercado, podem levá-lo a se especializar na produção destes bens e impedir a industrialização ou desencadear um processo de desindustrialização, inibindo o processo de desenvolvimento econômico. Essa doença está ligada a uma desindustrialização causada pela apreciação da taxa de câmbio real, sendo esta última uma externalidade negativa sobre os produtores de bens industriais decorrente da descoberta de recursos naturais escassos (BRESSER-PEREIRA, 2008). Ou seja, a abundância de recursos naturais induz a redução da participação da indústria no emprego e no valor adicionado por intermédio da apreciação cambial, resultando assim em perda de competitividade da indústria e déficit comercial crescente da mesma. Portanto, a desindustrialização causada pela "doença holandesa" está associada a déficits comerciais crescentes da indústria e superávits comerciais (crescentes) no setor não industrial.

Segundo Oreiro e Feijó (2010), a desindustrialização causada pela doença holandesa é também denominada de desindustrialização precoce, pois a mesma se iniciaria em um nível de renda per capita inferior ao observado nos países desenvolvidos quando os mesmos iniciaram o seu processo de desindustrialização. Desta forma, a doença holandesa faz com que os países por ela afetados se desindustrializem sem terem alcançado a maturidade industrial e, portanto, sem terem esgotado todas as possibilidades de desenvolvimento econômico que são permitidas pelo processo de industrialização.

Devemos destacar que o processo de desindustrialização pode ser desencadeado e ou facilitado pela política econômica adotada pelo país. As políticas de liberalização comercial e financeira, sugeridas pelo Consenso de Washington, fizeram com que o setor industrial de diversos países perdesse competitividade, reduzindo-se prematuramente. Diversos setores industriais, com vantagens comparativas dinâmicas, poderiam se tornar eficientes caso o processo de abertura comercial tivesse corrido de maneira seletiva e gradual. Nesse aspecto, Palma (2005) destaca que a doença holandesa da América latina foi um processo de desindustrialização descendente, pois foi induzida pela política macroeconômica de liberalização comercial e financeira. 
A hipótese de desindustrialização precoce de Palma destaca a sobreapreciação da taxa de câmbio real como um fator de extrema importância para explicar a redução da participação da indústria no valor adicionado. A sobreapreciação cambial é decorrente tanto de fatores conjunturais, como os fluxos de capital externo, quanto de fatores estruturais, como a doença holandesa. A doença holandesa seria uma motivação estrutural decorrente das vantagens comparativas ricardianas que o país possui na produção de bens primários.

No que se refere à taxa de câmbio, Bresser-Pereira (2008) afirma que nos países onde há a presença de doença holandesa existem duas taxas de equilíbrio: a taxa de câmbio de equilíbrio corrente e a de equilíbrio industrial. A taxa de câmbio de equilíbrio corrente seria aquela que equilibraria intertemporalmente a conta-corrente do balanço de pagamentos de um país, portanto é a taxa a qual o mercado deverá convergir. Já a taxa de câmbio de equilíbrio industrial seria aquela que viabilizaria a produção de bens comercializáveis no país, ou seja, seria aquela que permitiria que as empresas fossem competitivas utilizando suas tecnologias. O problema surge, pois a taxa de câmbio de equilíbrio corrente é estabelecida pelo mercado com base no custo marginal das mercadorias que dão origem à doença holandesa. No entanto, essa taxa de câmbio inviabiliza a competitividade dos setores que não possuem as rendas ricardianas, ou seja, os setores que produzem bens comercializáveis e que incorporam tecnologia em sua produção ${ }^{2}$.

Por fim, Gonçalves (2001) apresenta a ideia da hipótese da inserção regressiva. Essa hipótese envolve tanto a perda de competitividade internacional da indústria nacional, quanto o fenômeno da reprimarização da pauta exportadora. Ou seja, a partir do momento em que a indústria nacional começa a perder competitividade internacional, passa a ocorrer uma modificação na pauta de exportação do país, observando-se um aumento no peso dos produtos básicos. Destaca-se que enquanto o desempenho das exportações de manufaturados está ligado a fatores como a taxa de câmbio e o nível de investimento, o desempenho das exportações de produtos agrícolas dependem de forma mais acentuada de variáveis exógenas como nível de renda e preço mundial. Este fato é consequência do maior dinamismo presente no setor industrial em comparação ao setor agropecuário.

\footnotetext{
2 Devido à abundância de recursos naturais, a produção de produtos básicos ocorre a um custo baixo se comparado ao mercado internacional. Este fato faz surgir para o país às chamadas rendas ricardianas.
} 


\section{O setor industrial brasileiro e o debate sobre a desindustrialização}

Analisaremos nesta seção o setor industrial tendo como base a indústria de transformação ${ }^{3}$, pois esta é a classe industrial que mais se aproxima do conceito de "indústria manufatureira", em torno ao qual se aplicam as teses de desindustrialização.

Recapitulando, a desindustrialização, em seu sentido negativo, está relacionada à perda de participação do valor adicionado da indústria no PIB e do emprego industrial no emprego total. Analisaremos, portanto, estes dois fatos para verificarmos se há ou não evidências de desindustrialização no Brasil.

A evolução da participação do valor adicionado da indústria de transformação no PIB pode ser vista no gráfico 1 abaixo.

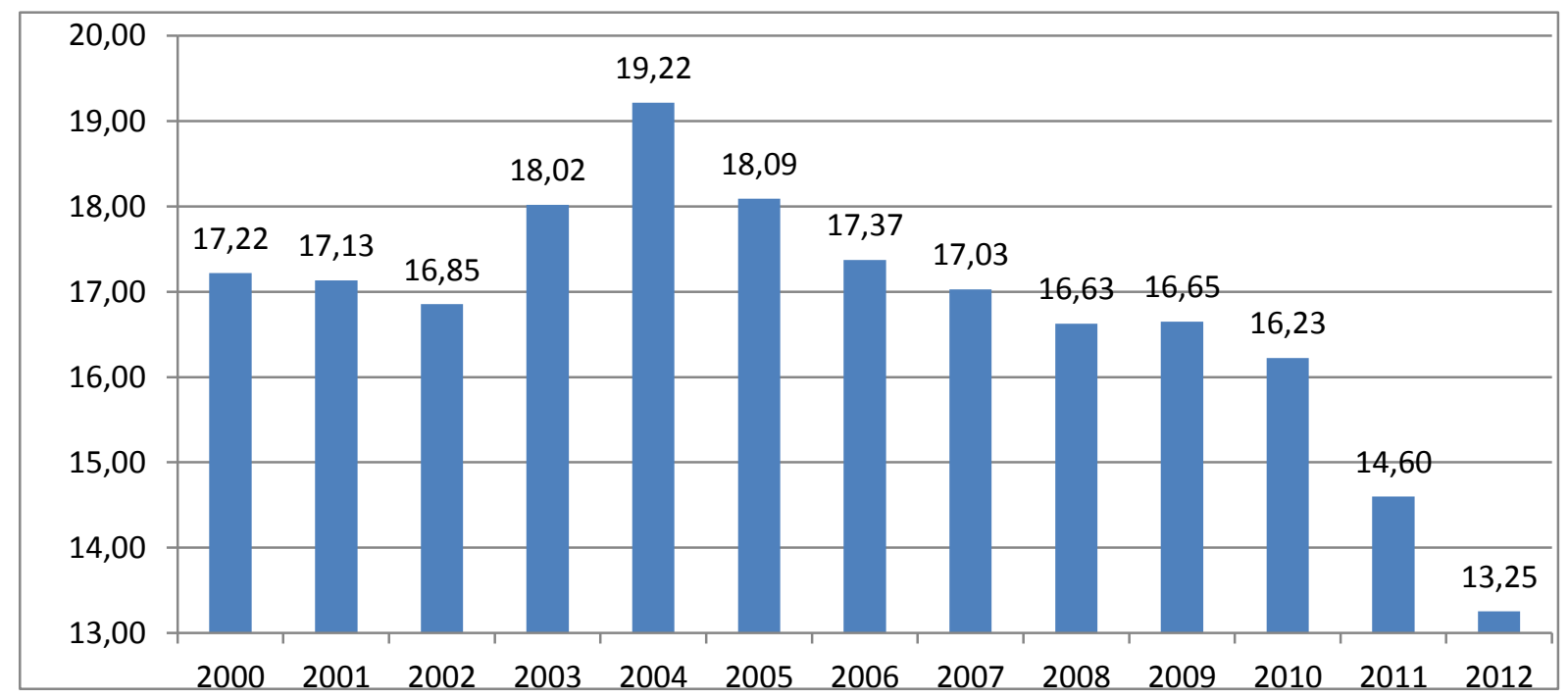

Gráfico 1: Participação (\%) da indústria de transformação no PIB - Brasil (2000-2012)

Fonte: Instituto Brasileiro de Geografia e Estatística (IBGE), Sistema de Contas Nacionais Referência 2000 (IBGE/SCN 2000 Anual); IPEADATA. Elaboração: Própria.

Obs.: em porcentagem do valor adicionado a preços básicos.

O padrão de crescimento brasileiro, a partir de 2004, foi marcado pelo chamado boom de commodities. Neste mesmo ano a indústria de transformação começa a perder espaço na economia. Essa perda de espaço é caracterizada por ser lenta e gradual, até o ano de 2010. No entanto, nos anos de 2011 e 2012 observamos um declínio mais acentuado.

Entre 2004 e 2008 o cenário econômico foi marcado pelo crescimento econômico mundial (média de 4,56\% ao ano), pelo crescimento das importações mundiais, pelo aumento

\footnotetext{
3 Segundo a Classificação Nacional de Atividades Econômicas (CNAE), as atividades da indústria de transformação envolvem a transformação física, química e biológica de materiais, substâncias e componentes com a finalidade de se obterem produtos novos. Os materiais, substâncias e componentes transformados são insumos produzidos nas atividades agrícolas, florestais, de mineração, da pesca e produtos de outras atividades industriais.
} 
dos preços dos produtos básicos e pela valorização cambial. Esses fatores influenciaram diretamente no aumento das exportações dos produtos básicos. No entanto, a valorização cambial e o alto grau de exposição da indústria brasileira à concorrência estrangeira levou a perda de competitividade do setor industrial nacional.

Como muito bem salientou Cavalcanti e Ribeiro (1998), o desempenho das exportações brasileiras de manufaturados depende, em grande medida, de condições pelo lado da oferta, como a capacidade produtiva e a rentabilidade do comércio exterior. Por outro lado, as exportações de produtos agrícolas parecem ser mais influenciadas por variáveis exógenas pelo lado da demanda, como nível de renda mundial e os preços internacionais. Desta forma, podemos concluir que a perda de dinamismo das exportações brasileiras de manufaturados pode ser atribuída, principalmente, a variáveis como taxa de câmbio e taxa de investimento. O gráfico 2 abaixo exemplifica a relação entre o câmbio e a quantidade produzida pela indústria de transformação. Podemos observar o quanto a produção da indústria de transformação é aderente à variação cambial.

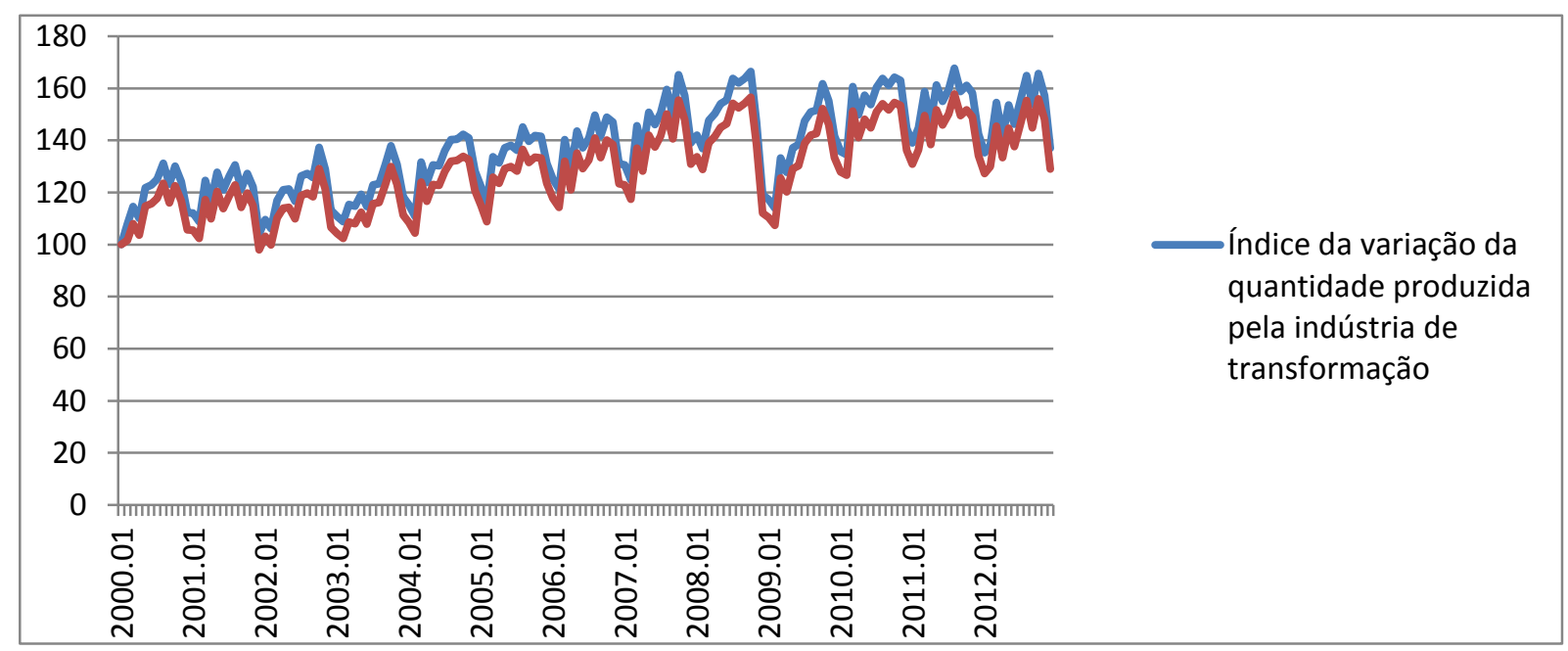

Gráfico 2: Variação dos índices de câmbio e da quantidade produzida pela indústria de transformação

Fonte: Instituto Brasileiro de Geografia e Estatística (IBGE) e Instituto de Pesquisa Econômica Aplicada (IPEA). Elaboração: Própria.

A perda de competitividade da indústria de transformação brasileira também está relacionada a outro fator. A partir de 2004 observa-se na economia brasileira um aumento da transferência de renda, influenciada, entre outros fatores, pela política salarial ${ }^{4}$, e uma expansão do crédito, que juntos elevaram a demanda doméstica e reduziram a taxa de desemprego. $\mathrm{O}$ mercado de trabalho mais aquecido levou a um aumento do custo da mão de

4 O salário mínimo passou de $\mathrm{R} \$ 260,00$ em 2004 para $\mathrm{R} \$$ 415,00 e $\mathrm{R} \$ 622,00$ em 2008 e 2012, respectivamente. 
obra, que não foi acompanhado pelo crescimento da produtividade da indústria de transformação, de forma que o custo unitário de produção aumentou ${ }^{5}$. Com o salário em alta, aliado ao fato do setor industrial ser produtor de bens comercializáveis (tradables) e, portanto, ter dificuldades para repassar o aumento dos custos para os preços devido à concorrência externa, houve uma redução na margem de lucro da indústria de transformação e um aumento da importação no período. Ou seja, a produção manufatureira no Brasil se tornou mais cara e, consequentemente, parte do aumento da demanda no período se destinou às importações. Portanto, a perda de participação da indústria de transformação no período está relacionada a fatores como: queda na produtividade, baixo índice de investimento, altos custos doméstico, valorização cambial e abertura comercial e financeira.

$\mathrm{Na}$ análise acima foi apresentado os dados e os motivos da diminuição da participação do valor adicionado da indústria de transformação no PIB. Agora, portanto, iremos analisar a participação do emprego industrial no emprego total. Novamente utilizaremos na análise a indústria de transformação.

A evolução da população ocupada na indústria de transformação e sua participação no total de ocupações estão representadas na tabela abaixo.

Tabela 1: Participação da ocupação dos setores no total de ocupações da economia

\begin{tabular}{|c|c|c|c|}
\hline Ano & Agropecuária & Indústria de transformação & Serviços \\
\hline 1995 & 26,0 & 13,0 & 54,3 \\
\hline 1996 & 24,6 & 12,8 & 55,5 \\
\hline 1997 & 24,5 & 12,3 & 56,0 \\
\hline 1998 & 23,8 & 11,6 & 56,8 \\
\hline 1999 & 24,3 & 11,7 & 56,5 \\
\hline 2000 & 22,3 & 12,0 & 58,2 \\
\hline 2001 & 21,2 & 11,8 & 59,5 \\
\hline 2002 & 21,0 & 11,7 & 59,8 \\
\hline 2003 & 21,0 & 11,9 & 59,9 \\
\hline 2004 & 21,4 & 12,2 & 59,3 \\
\hline 2005 & 20,9 & 12,8 & 59,1 \\
\hline 2006 & 19,7 & 12,5 & 60,7 \\
\hline 2007 & 18,6 & 12,8 & 61,4 \\
\hline 2008 & 17,8 & 13,0 & 61,3 \\
\hline 2009 & 17,4 & 12,7 & 62,1 \\
\hline
\end{tabular}

Fonte: Sistema de Contas Nacionais do IBGE (Referência 2000). Elaboração: Própria.

\footnotetext{
${ }^{5}$ De acordo com Ipea (2012), pelos dados das Contas Nacionais, a produtividade da indústria de transformação diminuiu $0,9 \%$ ao ano entre 2000 e 2009. No entanto, nesse mesmo período, a produtividade do trabalho aumentou em média $0,9 \%$ ao ano.
} 
Os dados do Sistema de Contas Nacionais estão disponíveis apenas até o ano de 2009. Esse fato, de certa forma, afetará a análise uma vez que o período em que há maior perda de participação do valor adicionado da indústria de transformação no PIB foi em 2011 e 2012. No entanto, ainda assim os dados serão úteis.

A análise do mercado de trabalho é utilizada por alguns estudiosos para refutar a hipótese do processo de desindustrialização no Brasil, tanto na década de 80 e 90, quanto atualmente no século XXI, como é o caso do trabalho de Wasques (2011). Analisando apenas os dados acima, podemos concluir que a participação das ocupações da indústria de transformação no total de ocupações permanece de certa forma estável entre 1995 e 2009. Esta conclusão está de acordo com a hipótese que nega o processo de desindustrialização no Brasil.

No entanto, devemos notar que a conclusão acima não leva em conta um importante fato: a influência do setor agropecuário na participação das ocupações da indústria de transformação no total de ocupações. O crescimento das ocupações em valor absoluto no setor de serviços é superior ao que ocorre na agropecuária e na indústria de transformação, resultando assim no crescimento de seu peso relativo durante os anos. O resultado desta tendência seria a diminuição da participação tanto da indústria de transformação quanto do setor agropecuário no total de ocupações. Entretanto, como vimos, a participação da indústria de transformação no total de ocupações permaneceu estável no período. Esta estabilidade está ocorrendo devido à diminuição do número de postos de trabalho no setor agropecuário, o que faz com que este setor perca participação tanto para a indústria de transformação quanto para o setor de serviços. Dessa forma, a participação da indústria de transformação no total de ocupações permanece estável, pois a perda de participação ocasionada pelo aumento das ocupações do setor de serviços é contrabalançada pela diminuição das ocupações referentes ao setor agropecuário ${ }^{6}$.

Portanto, a participação das ocupações da indústria de transformação no total de ocupações permaneceu constante no período entre 1996 e 2009 devido à diminuição da participação das ocupações do setor agropecuário nas ocupações totais. Em alguns anos houve até mesmo uma diminuição do valor absoluto de ocupações no setor agropecuário. Apenas entre 2002 e 2005, período de crescimento das exportações de commodities, houve uma

\footnotetext{
${ }^{6}$ Devemos frisar que, ao contrário do que acontece com as ocupações, a participação do valor adicionado da agropecuária no PIB permanece praticamente constante entre 1996 e 2009.
} 
melhora no total de ocupações, em termos absolutos, do setor agropecuário. A partir de 2006 este valor volta a cair continuamente.

Segundo o Censo Agropecuário (2006) do IBGE, entre 1996 e 2006, o pessoal ocupado nos estabelecimentos agropecuários diminuiu de 17,9 milhões de pessoas para 16,6 milhões de pessoas, ou seja, uma redução de 7,2\%. Essa queda pode ser explicada por fatores como o aumento da mecanização e a utilização de técnicas mais sofisticadas no setor 7 .

Segundo Buainain e Dedecca (2008), o aumento das áreas agrícolas com maior dinamismo está levando a uma redução absoluta da utilização de mão de obra, porém, há um aumento da demanda por mão de obra qualificada e especializada. Um bom exemplo dado pelos autores é a produção de algodão. O deslocamento ocorrido nos anos 90 da produção de algodão do estado de São Paulo para o Centro-Oeste e a mudança tecnológica eliminaram, em três anos, mais de 300 mil postos de trabalho ${ }^{8}$.

Por fim, há ainda outra hipótese, apresentada por Squeff (2012), para explicar a estabilidade da participação das ocupações da indústria de transformação no total de ocupações. Essa outra hipótese afirma que o fato do emprego industrial ser, de modo geral, mais qualificado que o emprego na agricultura e, em menor medida, que aquele verificado no setor de serviços, os empresários industriais tendem a postergar a demissão de seus funcionários em situações adversas. Além disso, há uma pressão do governo, em certos momentos, de impedir a demissão, como foi o caso do setor automobilístico durante a crise de 2008.

\section{Análise das exportações brasileiras por fator agregado}

Desde o ano de 2001 até 2012 o Brasil apresentou superávits na balança comercial. No entanto, ao longo dos anos, a pauta de exportação brasileira veio sofrendo uma transformação considerável no que se refere a sua composição entre produtos básicos, semimanufaturados e manufaturados. Essa evolução pode ser vista no gráfico abaixo.

\footnotetext{
${ }^{7}$ Exemplos de técnicas mais sofisticadas são o melhoramento genético de sementes e a adoção da semeadura direta em terrenos protegidos pelos resíduos da lavoura anterior, diminuindo as tradicionais operações de preparo do solo (aração e gradeação).

${ }^{8}$ Outro exemplo seria o setor sucroalcooleiro, onde estima-se que a mecanização da colheita da cana reduzirá de forma abrupta e significativa a demanda por trabalhadores. Segundo Delgado (2012), observou-se no estado do Paraná uma forte expansão do setor sucroalcooleiro, gerando um crescimento expressivo do número de empregos. No entanto, desde 2009 está havendo uma diminuição dos postos de trabalho em decorrência do processo de mecanização da colheita no Estado.
} 


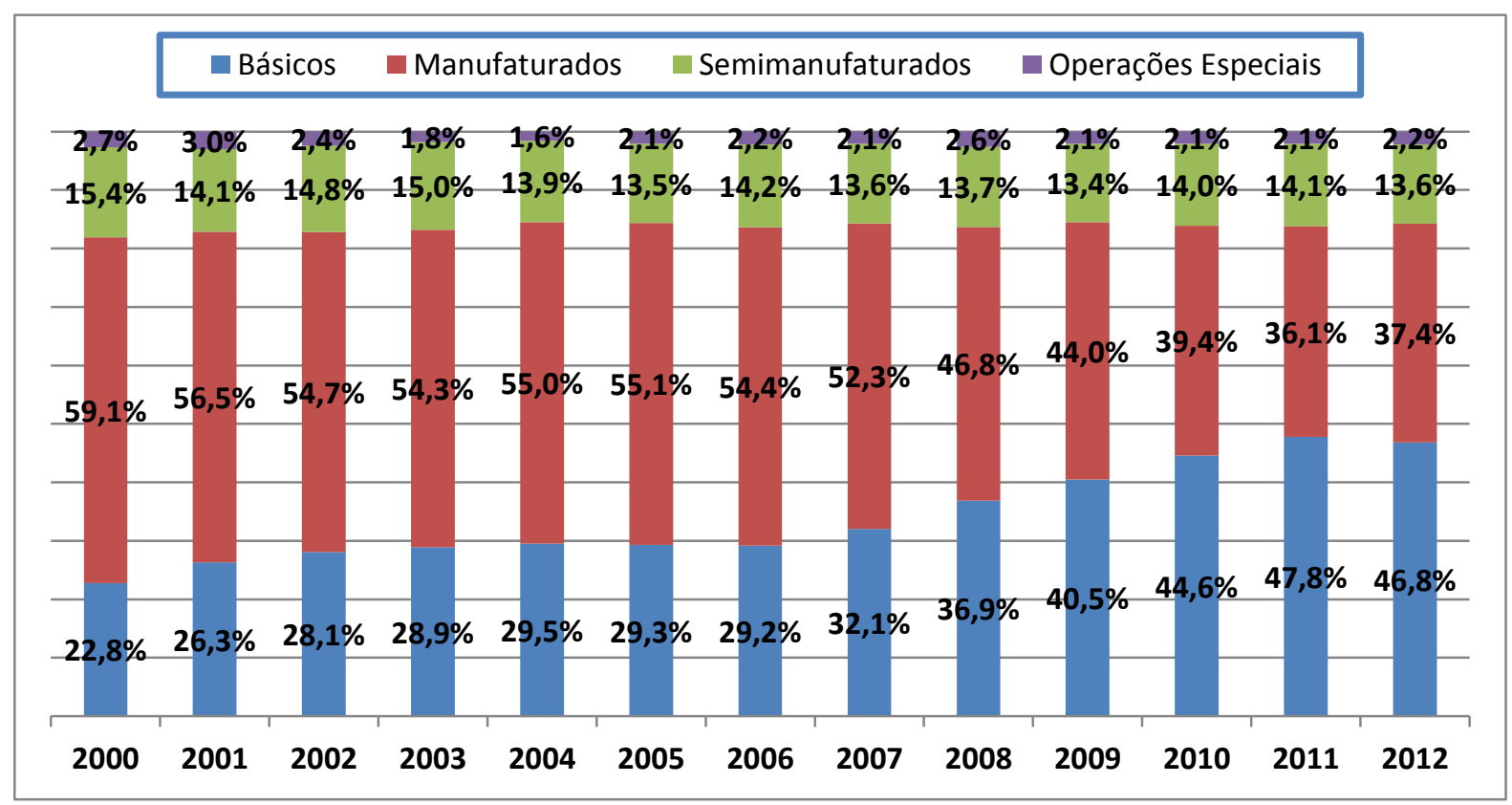

Gráfico 3: Composição das exportações brasileiras por fator agregado de 2000 a 2012. Fonte: SECEX/MDIC. Elaboração: Própria.

Analisando a evolução da composição das exportações brasileiras, podemos observar que o peso dos produtos semimanufaturados permanece estável entre os anos de 2000 e 2012, tendo seus valores máximo $(15,4 \%)$ e mínimo $(13,4 \%)$ uma diferença de apenas dois pontos percentuais. No entanto, ao longo do século XXI podemos observar um significativo aumento do peso dos produtos básicos na composição das exportações brasileiras. O ganho de participação dos produtos básicos na pauta de exportação brasileira, saindo de 22,8\% em 2000 para 46,8\% em 2012, possui como contrapartida a diminuição da participação dos produtos manufaturados, estes que representavam 59,1\% no ano 2000 e alcançaram o valor de 37,4\% em 2012. O resultado deste processo está representado no ano de 2010, quando os produtos básicos passaram a ter maior relevância que os produtos manufaturados na composição das exportações brasileiras.

Para obtermos um melhor conhecimento deste processo de modificação da pauta de exportação brasileira, devemos analisar a variação dos preços e das quantidades dos produtos básicos e manufaturados. Essas variações estão resumidas na tabela 2 abaixo. 
Tabela 2: Variação do preço e da quantidade exportada segundo fator agregado de 2000 a 2012

\begin{tabular}{|c|c|c|c|c|c|c|}
\hline \multirow{2}{*}{ Ano } & \multicolumn{3}{|c|}{ Variação do preço das exportações (\%) } & \multicolumn{3}{c|}{ Variação da quantidade das exportações (\%) } \\
\cline { 2 - 7 } & Básicos & Semimanufaturados & Manufaturados & Básicos & Semimanufaturados & Manufaturados \\
\hline $\mathbf{2 0 0 0 - 2 0 0 1}$ & $-8,4$ & $-10,5$ & $-0,1$ & 33,3 & 8,3 & 1,3 \\
\hline $\mathbf{2 0 0 1 - 2 0 0 2}$ & $-4,1$ & $-4,6$ & $-4,6$ & 15,2 & 14,0 & 5,2 \\
\hline $\mathbf{2 0 0 2 - 2 0 0 3}$ & 10,4 & 11,3 & $-0,6$ & 13,1 & 9,7 & 21,0 \\
\hline $\mathbf{2 0 0 3 - 2 0 0 4}$ & 18,9 & 14,5 & 6,0 & 13,3 & 7,2 & 26,1 \\
\hline $\mathbf{2 0 0 4 - 2 0 0 5}$ & 13,7 & 11,8 & 11,0 & 7,1 & 6,3 & 10,8 \\
\hline $\mathbf{2 0 0 5 - 2 0 0 6}$ & 9,4 & 18,1 & 12,4 & 6,1 & 3,5 & 2,2 \\
\hline $\mathbf{2 0 0 6 - 2 0 0 7}$ & 14,5 & 10,9 & 8,4 & 11,8 & 0,7 & 3,2 \\
\hline $\mathbf{2 0 0 7 - 2 0 0 8}$ & 41,2 & 25,3 & 16,2 & 0,2 & $-0,9$ & $-5,0$ \\
\hline $\mathbf{2 0 0 8 - 2 0 0 9}$ & $-17,5$ & $-20,3$ & $-5,8$ & 2,9 & $-5,0$ & $-22,8$ \\
\hline $\mathbf{2 0 0 9 - 2 0 1 0}$ & 30,4 & 29,0 & 8,5 & 11,4 & 6,6 & 8,9 \\
\hline $\mathbf{2 0 1 0 - 2 0 1 1}$ & 31,3 & 20,9 & 14,0 & 3,6 & 5,6 & 1,7 \\
\hline $\mathbf{2 0 1 1 - 2 0 1 2}$ & $-8,2$ & $-6,8$ & $-0,3$ & 0,9 & $-1,6$ & $-1,3$ \\
\hline
\end{tabular}

Fonte: FUNCEX. Elaboração: Própria

Analisando os dados acima podemos observar que entre 2000 e 2002 o fator primordial que explica o aumento do peso dos produtos básicos nas exportações brasileiras é a variação na quantidade vendida. Já entre 2002 e 2003 a explicação é dada pelo aumento dos preços dos produtos básicos. Entre 2003 e 2005 observamos uma retomada do aumento do peso dos produtos manufaturados. Esse aumento ocorreu principalmente devido ao crescimento excepcionalmente elevado das vendas neste período e, aliado a este fato, houve movimento favorável na variação dos preços. De 2005 em diante observamos que, de uma forma geral, tanto a variação da quantidade exportada quando dos preços dos produtos básicos em relação aos manufaturados explicam o aumento do peso dos produtos básicos na pauta de exportação brasileira.

Podemos constatar que o argumento de que a piora do desempenho do setor manufatureiro se deve, mais recentemente, apenas aos efeitos da crise internacional de 20082009 tem relevância limitada. Desde o ano de 2005 a variação da quantidade exportada de manufaturados vem decrescendo, sendo, no entanto, a diminuição mais relevante no período da crise internacional de 2008-2009. Isso indica que o setor exportador manufatureiro brasileiro vem perdendo mercado desde antes da crise internacional, uma vez que entre 2005 e 2008 o valor das importações mundiais de bens manufaturados cresceu continuamente.

Uma boa variável para observarmos a possível perda de mercado do setor manufatureiro brasileiro é a participação das exportações brasileiras de manufaturados nas 
importações mundiais de manufaturados. Os valores desta variável podem ser vistos no gráfico 4.

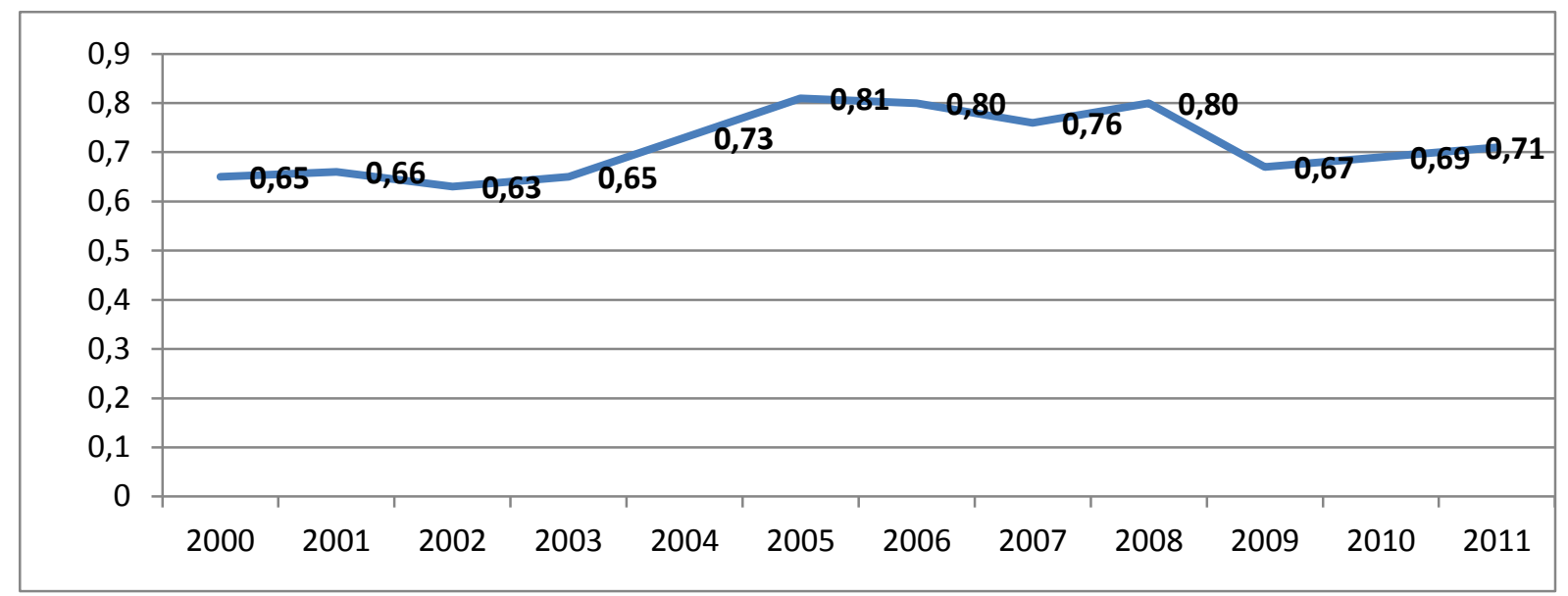

Gráfico 4: Peso das exportações brasileiras de manufaturados nas importações mundiais de manufaturados Fonte: OMC. Elaboração: Própria.

O gráfico 4 nos mostra que no ano de 2000 o peso das exportações brasileiras de manufaturados nas importações mundiais de manufaturados representava $0,65 \%$, teve significativa melhora até 2005, alcançando o valor de 0,81\%. A partir de 2006 este valor se reduziu, chegando a 0,67\% em 2009. Em 2010 e 2011 este valor apresentou relativa melhora, alcançando o valor de $0,71 \%$ em 2011.

O Brasil apresentou uma perda de market-share considerável nas exportações de manufaturados entre 2008 e 2009, saindo de $0,80 \%$ para $0,67 \%$. Este fato poderia ser creditado à crise internacional e a consequente redução das importações mundiais de manufaturados. No entanto, em 2010, o valor das importações de manufaturados voltou a crescer e, em 2011, este valor ultrapassou o valor pré-crise. Apesar deste fato, o market-share brasileiro de manufaturados alcançou apenas o valor de 0,71\%, valor bem abaixo do alcançado no período pré-crise. A conclusão é que pode estar ocorrendo no Brasil uma perda de competitividade internacional do setor manufatureiro, resultando assim na perda de participação no mercado internacional.

Um exemplo da diminuição das exportações de produtos manufaturados é dado por Almeida e Souza (2013). Segundo os autores, a participação dos produtos manufaturados na pauta de exportação brasileira tanto para os Estados Unidos da América (EUA) quanto para a América Latina e Caribe vem diminuindo constantemente. Somente para a América Latina e 
Caribe, a participação dos produtos manufaturados no total exportado saiu de $88,22 \%$ em 2000 para $70,28 \%$ em 2009.

A piora do desempenho das exportações brasileiras de manufaturados pode ser creditada a política econômica e a problemas de competitividade do país, como, por exemplo, o chamado "custo Brasil". A junção dos problemas estruturais da economia brasileira com a política macroeconômica adotada desde a década de 1990, fundamentada nas práticas defendidas pelo Consenso de Washington, estabelece uma limitação ao crescimento sustentado das exportações, principalmente das exportações de manufaturas.

O que acontece é que o país não consegue combinar crescimento do produto com o crescimento das exportações de manufaturados. A ocorrência desse fato se dá devido ao baixo nível de investimento aliado a tentativa de manutenção de uma taxa de inflação reduzida e a eliminação da vulnerabilidade externa por meio da geração de déficits sustentáveis em conta corrente do balanço de pagamentos. O processo ocorre de forma que a elevação da taxa de crescimento do produto da economia não é acompanhada pelo aumento consistente da taxa de investimento, resultando assim no surgimento de déficits em transações correntes. $\mathrm{O}$ crescimento da renda interna leva a um aumento das importações e a falta de investimentos deprime a capacidade do país em atender a demanda interna crescente. $\mathrm{O}$ aumento da demanda doméstica é incapaz de estimular os investimentos e a produção industrial doméstica devido, por exemplo, ao câmbio valorizado, o qual barateia e estimula as importações. A taxa de câmbio é recorrentemente mantida valorizada, pois esta é utilizada como forma de conter a inflação e diminuir a vulnerabilidade externa. Aliada a valorização cambial, o elevado nível da taxa de juros básica (utilizada para conter a inflação de demanda e atrair capital via conta financeira do balanço de pagamentos) contribui para a diminuição do nível de investimento, principalmente no setor manufatureiro.

Dado o que foi dito acima, a ocorrência de crescimento econômico sem a piora do saldo comercial tornou-se dependente no Brasil do aumento do valor das exportações de produtos básicos, como as commodities. Quando este aumento ocorre devido à variação favorável do preço dos produtos básicos, há um estímulo a produção destes frente aos produtos manufaturados. Além disso, o fato do Brasil possuir vantagens comparativas na produção de produtos básicos (como clima favorável e terras férteis) e a grande concorrência internacional presente nos mercados de produtos manufaturados são outros fatores que 
desestimulam o aumento do nível de investimento no setor manufatureiro, resultando na perda de competitividade do setor manufatureiro nacional.

Como muito bem frisou Squeff (2012), entre os efeitos esperados de um aumento nos preços de commodities estão a elevada apreciação cambial, o aumento nos gastos do governo em função do aumento da receita proveniente de impostos e royalties, o aumento nos preços dos bens não comercializáveis em comparação aos bens comercializáveis, a transferência de recursos e a realocação de fatores de produção dos setores comercializáveis (exceto commodities) para os setores produtores de matérias-primas e de não comercializáveis devido aos maiores retornos nestes dois últimos e, por fim, o déficit em conta corrente no longo prazo.

Assim, como alguns autores já afirmaram, esse processo de aumento do preço das commodities será efetivamente considerado uma doença na medida em que a taxa de câmbio valorizada desestimula as exportações, seja custoso ao país ajustar suas contas fiscais quando há reversão dos preços das commodities, gera-se uma distorção de preços relativos e repasse do aumento dos preços das commodities para a inflação doméstica, falta recursos para fomentar atividades de alto conteúdo tecnológico, surge a possibilidade de haver uma especialização excessiva na fabricação de alguns produtos a despeito das vantagens comparativas (estáticas) de cada país e por fim, o país passa a ter dificuldades de financiar o déficit em conta corrente quando houver mudança nos preços das commodities (SQUEFF, 2012).

Portanto, a diminuição do peso dos produtos manufaturados na pauta de exportação brasileira está relacionada a fatores como a política de câmbio valorizado, taxa básica de juros elevada, baixa taxa de investimento (tanto na produção quanto em pesquisa e desenvolvimento e infraestrutura) e ao aumento dos preços dos produtos básicos no mercado internacional. Podemos observar que apenas o último fator não está ligado à política econômica adotada pelo governo brasileiro. Tendo isso em mente, uma possível solução para este problema seria o governo estimular os investimentos industriais por meio de isenções fiscais (de forma a reduzir os custos empresariais), incentivos financeiros e investimentos em infraestrutura. Além disso, seria extremamente importante que o governo apoiasse e incentivasse políticas nacionais ligadas ao desenvolvimento de novas tecnologias, ou seja, incentivo ao investimento em Ciência e Tecnologia (C\&T). Todos esses fatores atuariam no longo prazo de forma a melhorar (qualitativamente e/ou quantitativamente) a oferta interna de 
produtos, reduzir os custos e aumentar a eficiência da economia, ajudando assim no controle da inflação e, consequentemente, aliviando ou eliminando as barreiras aos investimentos industriais estabelecidas pala valorização cambial e pela adoção de uma alta taxa básica de juros.

\section{Análise da participação dos setores industriais por intensidade tecnológica no setor externo brasileiro}

Observamos na seção anterior que a proporção dos bens manufaturados na pauta de exportação brasileira vem diminuindo nos últimos anos. Nesta seção, para complementar a análise, observaremos o comportamento das exportações do setor industrial segundo intensidade tecnológica. Faremos uma análise das exportações, importações e do saldo comercial do setor industrial, segundo a intensidade tecnológica.

A composição e o comportamento nos últimos anos das exportações brasileiras dos setores industriais por intensidade tecnológica estão resumidos na tabela abaixo.

Tabela 3: Participação da exportação Brasileira dos Setores Industriais por Intensidade Tecnológica (\%) nas exportações totais entre 2000 e 2012 - Classificação extraída da OCDE.

\begin{tabular}{|c|c|c|c|c|c|c|}
\hline Ano/Grupo & Baixa & $\begin{array}{c}\text { Média- } \\
\text { baixa }\end{array}$ & $\begin{array}{c}\text { Média- } \\
\text { alta }\end{array}$ & Alta & Total & $\begin{array}{c}\text { Não } \\
\text { industriais }\end{array}$ \\
\hline $\mathbf{2 0 0 0}$ & 29,3 & 18,6 & 23,1 & 12,4 & 83,4 & 16,6 \\
\hline $\mathbf{2 0 0 1}$ & 31,7 & 17,1 & 21,2 & 12,0 & 82,0 & 18,0 \\
\hline $\mathbf{2 0 0 2}$ & 31,7 & 17,6 & 21,4 & 9,8 & 80,6 & 19,4 \\
\hline $\mathbf{2 0 0 3}$ & 31,9 & 18,3 & 22,8 & 7,0 & 80,1 & 19,9 \\
\hline $\mathbf{2 0 0 4}$ & 30,5 & 19,5 & 23,1 & 6,9 & 80,0 & 20,0 \\
\hline $\mathbf{2 0 0 5}$ & 28,4 & 19,2 & 24,4 & 7,4 & 79,5 & 20,5 \\
\hline $\mathbf{2 0 0 6}$ & 27,9 & 19,8 & 23,6 & 6,8 & 78,1 & 21,9 \\
\hline $\mathbf{2 0 0 7}$ & 27,1 & 19,7 & 22,7 & 6,4 & 75,9 & 24,1 \\
\hline $\mathbf{2 0 0 8}$ & 26,0 & 19,6 & 20,3 & 5,8 & 71,7 & 28,3 \\
\hline $\mathbf{2 0 0 9}$ & 28,5 & 16,2 & 17,8 & 5,9 & 68,4 & 31,6 \\
\hline $\mathbf{2 0 1 0}$ & 26,4 & 14,6 & 18,0 & 4,6 & 63,6 & 36,4 \\
\hline $\mathbf{2 0 1 1}$ & 24,1 & 15,3 & 16,6 & 3,8 & 59,8 & 40,2 \\
\hline $\mathbf{2 0 1 2}$ & 24,7 & 16,0 & 16,7 & 4,2 & 61,6 & 38,4 \\
\hline
\end{tabular}

Fonte: SECEX/MDIC. Elaboração: Própria.

O primeiro aspecto a se observar na tabela 3 é a perda de participação nas exportações totais dos produtos industriais de alta intensidade tecnológica. Do ano 2000 em diante, exceto os anos de 2005 e 2012, as exportações industriais de alta intensidade tecnológica decaíram constantemente, saindo de uma participação de 12,4\% em 2000 para 4,2\% em 2012. Dentre os 
setores que contribuíram para esta queda podemos citar os setores de Aeronáutica e Aeroespacial, Material de escritório e informática e Equipamentos de rádio, televisão e comunicação.

Um segundo aspecto é a queda da participação dos produtos industriais de média-alta tecnologia. Esta queda teve inicio no ano de 2005, apesar de menos significativa do que a apresentada pelo setor industrial de alta tecnologia, também pode ser considerada importante já que ocorreu uma perda de quase oito pontos percentuais entre os anos de 2005 e 2012. O principal setor que contribuiu para esta diminuição foi o setor de Veículos automotores, reboques e semi-reboques.

Outro aspecto que podemos visualizar é a relativa estabilidade da participação do setor industrial de média-baixa tecnologia nas exportações brasileiras. Devemos destacar que este setor apresenta grande influência das exportações de produtos metálicos. Entre 2000 e 2012, o setor de produtos metálicos respondeu por aproximadamente $60 \%$ das exportações do setor industrial de média-baixa tecnologia.

Com relação à participação do setor industrial de baixa tecnologia nas exportações brasileiras, podemos observar uma pequena perda de participação a partir de 2010. Entre 2000 e 2009 houve uma relativa estabilidade e esta foi marcada por modificação na participação dos setores que compõem a indústria de baixa tecnologia. Enquanto setores como o de Alimentos, bebidas e tabaco aumentaram sua participação, outros (como Produtos manufaturados e bens reciclados; Madeira e seus produtos; papel e celulose; e Têxteis, couro e calçados) tiveram sua participação reduzida.

Portanto, pela análise da tabela 3 concluímos que os setores industriais de alta e média-alta intensidade tecnológica estão perdendo participação nas exportações brasileiras enquanto que os setores de baixa e média-baixa intensidade tecnológica apresentam relativa estabilidade. Outro destaque é o aumento do peso das exportações não industriais frente aos produtos industriais. Desta forma, podemos concluir que a perda de participação dos setores industriais de alta e média-alta intensidade tecnológica está sendo contrabalançada pelo aumento da participação dos produtos não industriais. Esse resultado indica, no mínimo, um processo de reprimarização da pauta de exportação brasileira.

Neste momento cabe uma importante observação. Um dos resultados apresentado na seção anterior era de que há indícios de que esteja ocorrendo uma perda de competitividade internacional da indústria brasileira. Este fato, aliado à conclusão do parágrafo anterior de que 
está em vigência no Brasil um processo de reprimarização da pauta de exportação, corrobora a hipótese de Gonçalves (2001) do processo de inserção regressiva do Brasil no sistema mundial de comércio.

Outro importante ponto a ser destacado é o fato de que a elasticidade renda das importações de manufaturas é maior do que a elasticidade renda das importações de produtos básicos e de commodities. Desta forma, o aumento do peso dos produtos industriais na pauta de exportação brasileira é de extrema importância para aliviar a restrição de balanço de pagamentos $^{9}$ ao crescimento de longo prazo. No entanto, estamos observando que está ocorrendo no Brasil um processo inverso ao desejável, o que nos leva a esperar dificuldades futuras.

No que diz respeito às importações, a tabela abaixo resume sua composição por setores industriais e por intensidade tecnológica.

Tabela 4: Participação das importações Brasileiras dos Setores Industriais por Intensidade Tecnológica (\%) nas importações totais entre 2000 e 2012 - Classificação extraída da OCDE.

\begin{tabular}{|c|c|c|c|c|c|c|}
\hline Ano/Grupo & Baixa & $\begin{array}{c}\text { Média- } \\
\text { baixa }\end{array}$ & $\begin{array}{c}\text { Media- } \\
\text { alta }\end{array}$ & Alta & Total & $\begin{array}{c}\text { Não } \\
\text { industriais }\end{array}$ \\
\hline $\mathbf{2 0 0 0}$ & 8,4 & 15,7 & 38,4 & 25,4 & 88,0 & 12,0 \\
\hline $\mathbf{2 0 0 1}$ & 7,4 & 14,9 & 41,4 & 24,9 & 88,5 & 11,5 \\
\hline $\mathbf{2 0 0 2}$ & 7,7 & 14,1 & 42,1 & 22,1 & 86,0 & 14,0 \\
\hline $\mathbf{2 0 0 3}$ & 6,9 & 14,1 & 41,4 & 21,6 & 83,9 & 16,1 \\
\hline $\mathbf{2 0 0 4}$ & 6,5 & 13,8 & 39,4 & 22,5 & 82,2 & 17,8 \\
\hline $\mathbf{2 0 0 5}$ & 6,4 & 14,2 & 38,6 & 23,3 & 82,6 & 17,4 \\
\hline $\mathbf{2 0 0 6}$ & 6,8 & 15,7 & 36,5 & 23,2 & 82,2 & 17,8 \\
\hline $\mathbf{2 0 0 7}$ & 6,9 & 16,3 & 38,7 & 21,0 & 82,9 & 17,1 \\
\hline $\mathbf{2 0 0 8}$ & 6,8 & 16,9 & 40,0 & 19,3 & 82,7 & 17,3 \\
\hline $\mathbf{2 0 0 9}$ & 8,0 & 14,5 & 42,1 & 21,5 & 86,1 & 13,9 \\
\hline $\mathbf{2 0 1 0}$ & 7,6 & 18,8 & 41,4 & 19,7 & 87,6 & 12,4 \\
\hline $\mathbf{2 0 1 1}$ & 8,1 & 19,3 & 41,5 & 18,0 & 86,8 & 13,2 \\
\hline $\mathbf{2 0 1 2}$ & 8,3 & 18,7 & 41,7 & 18,5 & 87,2 & 12,8 \\
\hline
\end{tabular}

Fonte: SECEX/MDIC. Elaboração: Própria

A primeira conclusão que podemos extrair da tabela 4 é a alta participação dos produtos industriais nas importações brasileiras, com destaque aos produtos de média-alta tecnologia. A relação entre o peso dos produtos industriais com os não industriais possui

\footnotetext{
${ }^{9}$ Mais especificamente, o aumento do peso dos produtos industriais na pauta de exportação brasileira seria importante para equilibrar a conta corrente do balanço de pagamentos, uma vez que o Brasil é historicamente deficitário nas contas de renda e serviços.
} 
pouca variação no período, atingindo em 2012 um patamar muito próximo ao verificado no ano 2000 .

As importações de produtos industriais de alta intensidade tecnológica vêm perdendo peso de forma muito tímida nos últimos anos. Um exemplo deste fato seria o setor de Material de escritório e informática que perdeu participação nas importações, saindo de 3,5\% em 2000 para $1,9 \%$ em 2011.

As importações brasileiras de produtos industriais se concentram no grupo de médiaalta intensidade tecnológica. Podemos destacar neste grupo setores como Veículos automotores, reboques e semi-reboques, Produtos químicos e Máquinas e equipamentos mecânicos. O peso desses setores nas importações brasileiras no ano de 2011 era, respectivamente, de $10,5 \%, 14,9 \%$ e $11,6 \%$.

Com relação aos grupos de média-baixa e baixa tecnologia, observamos uma baixa variação e um valor muito próximo nos anos 2000 e 2012. No grupo de média-baixa tecnologia podemos destacar os setores de Produtos de petróleo refinado e outros combustíveis e os Produtos metálicos, que representavam, respectivamente, 9,1\% e 6,5\% das importações em 2011. Já no grupo de baixa intensidade tecnológica podemos destacar o setor de Alimentos, bebidas e tabaco que representou em 2011 3,2\% das importações brasileiras.

Prosseguindo o estudo sobre setor externo brasileiro, dado que acabamos de destrinchar a composição das exportações e importações brasileiras industriais por intensidade tecnológica, analisaremos agora o saldo comercial brasileiro segundo o setor não industrial e os setores industriais por intensidade tecnológica. Os valores deste saldo comercial foram resumidos na tabela abaixo. 
Tabela 5: Saldo comercial brasileiro dos Setores Industriais por Intensidade Tecnológica (em US\$ milhões)

\begin{tabular}{|c|c|c|c|c|c|c|c|}
\hline \multirow{2}{*}{ Ano/Setores } & \multicolumn{5}{|c|}{ Setor Industrial } & \multirow{2}{*}{$\begin{array}{l}\text { Setor não } \\
\text { Industrial }\end{array}$} & \multirow{2}{*}{$\begin{array}{c}\text { Saldo comercial } \\
\text { Total }\end{array}$} \\
\hline & Baixa & Média-baixa & Média-alta & Alta & Total & & \\
\hline 2000 & 11.435 & 1.434 & -8.695 & -7.342 & -3.168 & 2.403 & -765 \\
\hline 2001 & 14.365 & 11.725 & -10.719 & -6.842 & -1.470 & 4.091 & 2.621 \\
\hline 2002 & 15.481 & 3.979 & -6.935 & -4.525 & 8.000 & 5.119 & 13.119 \\
\hline 2003 & 19.962 & 6.594 & -3.292 & -5296 & 17.968 & 6.791 & 24.759 \\
\hline 2004 & 25.324 & 10.182 & -2.447 & -7.548 & 25.511 & 8.129 & 33.640 \\
\hline 2005 & 28.862 & 12.257 & 494 & -8.377 & 33.235 & 11.473 & 44.708 \\
\hline 2006 & 32.084 & 12.914 & -908 & -11.839 & 32.251 & 13.869 & 46.120 \\
\hline 2007 & 35.178 & 11.950 & -10.126 & -15.044 & 21.958 & 18.070 & 40.028 \\
\hline 2008 & 40.158 & 9.648 & -29.169 & -21.932 & -1.294 & 26.040 & 24.746 \\
\hline 2009 & 33.423 & 6.144 & -26.504 & -18.431 & -5.368 & 30.640 & 25.272 \\
\hline 2010 & 39.440 & -4.712 & -38.983 & -26.497 & -30.753 & 51.019 & 20.266 \\
\hline 2011 & 43.593 & -4.570 & -51.843 & -30.409 & -43.230 & 73.026 & 29.796 \\
\hline 2012 & 41.462 & -2.902 & -52.473 & -31.118 & -45.031 & 64.439 & 19.408 \\
\hline
\end{tabular}

Fonte: SECEX/MDIC. Elaboração: Própria.

O saldo comercial total brasileiro é superavitário desde o ano 2001. Observa-se que o valor deste saldo cresce rapidamente até o ano de 2006, sendo explicado tanto pela melhora das contas do setor não industrial quanto pela melhora das contas agregadas do setor industrial. A partir do ano de 2007 este saldo superavitário começa a declinar por influência da piora das contas agregadas do setor industrial, uma vez que o saldo do setor não industrial é crescente durante praticamente todo o período a partir do ano 2000 e é devido a este setor que o saldo comercial brasileiro não teve um decréscimo ainda maior. Este declínio do saldo comercial total se estende até o ano de 2011, quando ocorre uma reversão momentânea, e já em 2012 este valor volta a decrescer.

No que diz respeito aos setores industriais, as tabelas 3 e 4 apresentadas anteriormente ajudam a explicar os dados da tabela 5. Enquanto o setor industrial de baixa intensidade tecnológica era o setor preponderante das exportações brasileiras, nas importações este apresentava o menor peso. Este fato ajuda a explicar o motivo deste setor apresentar superávits durante todo o período, com exceção do ano de 2009. O setor de Alimentos, bebidas e tabaco é um ótimo exemplo para o setor industrial de baixa intensidade tecnológica, pois possui representatividade tanto nas importações quanto nas exportações. $O$ saldo comercial deste setor foi superavitário durante todo o período, e alcançou no ano de 2011 o valor de US\$ 38.917 milhões. 
O setor industrial de alta intensidade tecnológica apresentou déficit em todo o período. Esses déficits são crescentes de 2003 a 2012, com exceção do ano de 2009, e são explicados preponderantemente pela diminuição das exportações. Já o saldo do setor de média-alta intensidade tecnológica, que também é negativo durante basicamente todo o período, observamos dois saltos do déficit entre os anos 2006 e 2007 e entre 2007 e 2008. Esses saltos ocorreram devido ao aumento das importações, facilitada pela valorização cambial no período. Um bom exemplo é o setor de Produtos químicos que saiu de um patamar de importação de US\$13.596 milhões em 2006 para alcançar US\$ 19.033 milhões e US\$ 28.881 milhões em 2007 e 2008, respectivamente.

Podemos concluir que os setores de média-alta e alta intensidade tecnológica são deficitários durante o período coberto pelo estudo e, além disso, seus respectivos déficits vêm aumentando nos últimos anos. O setor de média-baixa intensidade tecnológica, que foi superavitário até o ano de 2009, passou a ser deficitário no ano de 2010 devido primordialmente ao rápido crescimento das importações. Contrabalançando a tendência deficitária apresentada nos últimos anos pelos setores de média-baixa, média-alta e alta intensidade tecnológica, o setor de baixa intensidade tecnológica apresentou superávits crescentes nos últimos anos, com exceção do ano de 2009. Constatamos, portanto, que os dados relativos ao setor externo nos apresentam um cenário no mínimo preocupante com relação ao desempenho da indústria e sua relevância no processo de equilíbrio externo e crescimento econômico.

A conclusão acima de déficits crescentes do setor industrial, principalmente os referentes aos setores de média-alta e alta intensidade tecnológica, pode ser um reflexo da queda de participação do valor agregado da indústria de transformação no PIB. Esses dois fatos são utilizados por alguns estudiosos para defender a hipótese de doença holandesa no Brasil, uma vez que a desindustrialização causada pela doença holandesa está associada a déficits comerciais crescentes da indústria e superávits comerciais (crescentes) no setor não industrial. 
Para finalizar a análise do setor externo brasileiro devemos verificar a influência da taxa de câmbio no seu comportamento. Por meio do gráfico 5 podemos observar a evolução da taxa de câmbio efetiva real entre os anos 2000 e 2012.

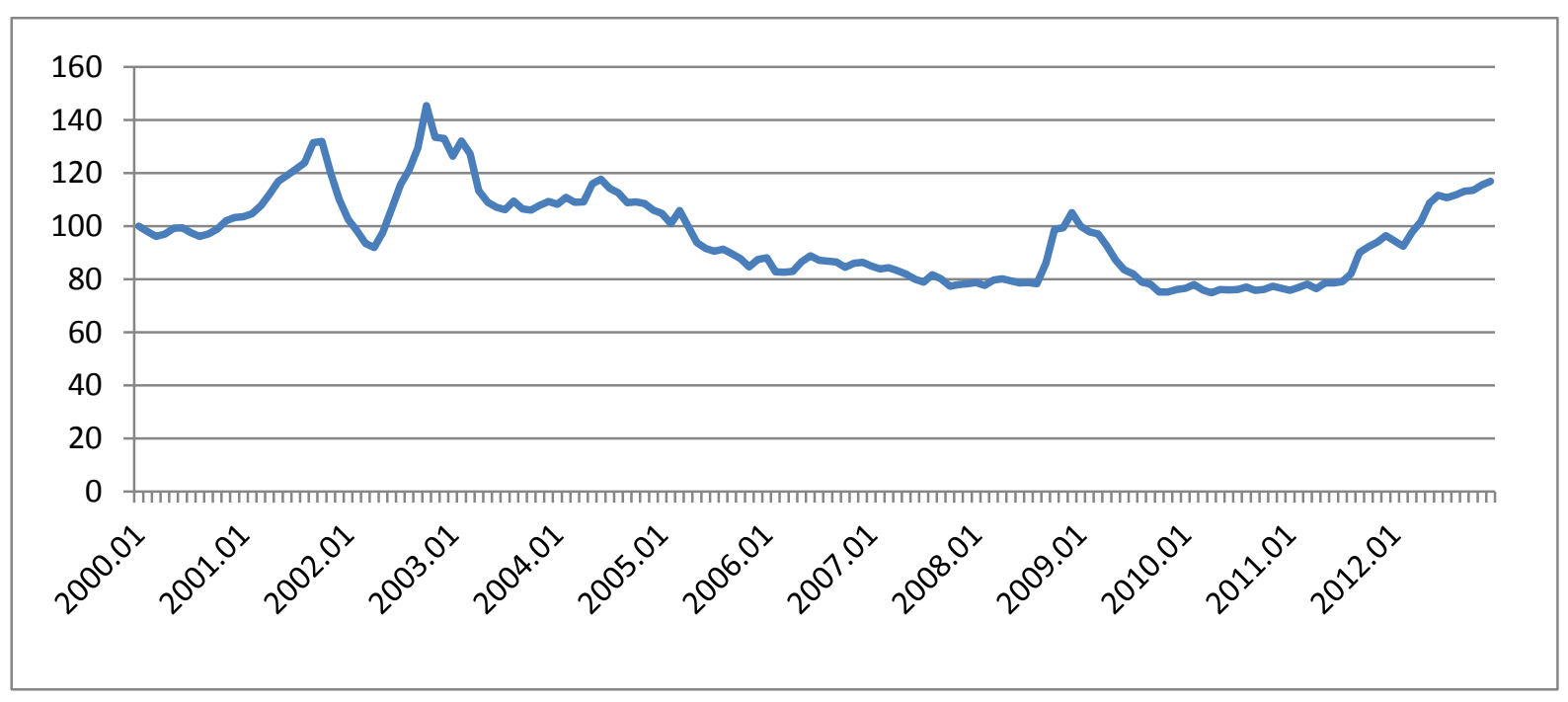

Gráfico 5: Evolução da taxa de câmbio efetiva real (INPC) entre 2000 e 2012 - índice (média $2000=100)$

Fonte: IPEA. Elaboração: Própria.

A desvalorização cambial em 2001, juntamente com a variação positiva da quantidade exportada, ajudou a contrabalançar a variação negativa dos preços neste ano. Após a desvalorização cambial em 2002, a taxa de câmbio apresentou uma tendência contínua à valorização até meados de 2008. O câmbio altamente valorizado, que perdurou até início de 2012, com exceção de um curto período entre 2008 e 2009, não afetou de forma considerável o resultado (saldo) externo devido, principalmente, a variação positiva dos preços e das quantidades exportadas dos produtos básicos. Este período também foi caracterizado por um aumento contínuo das importações mundiais.

A valorização cambial a partir de 2003 não impediu a permanência de um elevado saldo comercial até $2007^{10}$, devido basicamente aos produtos básicos e industriais de baixa intensidade tecnológica. $\mathrm{O}$ valor exportado nesse período aumentou devido à elevação dos preços das commodities e ao crescimento mais intenso de sua demanda. De fato, o comportamento dos produtos básicos e industriais de baixa intensidade tecnológica manteve a balança comercial brasileira superavitária no período, eliminando assim a necessidade de ajuste cambial. A permanência da taxa de câmbio valorizada, aliada ao elevado patamar da taxa de juros interna, contribuiu para agravar a situação do setor industrial brasileiro, tornando

${ }^{10} \mathrm{O}$ saldo comercial diminui consideravelmente a partir de 2008 devido à crise econômica mundial. 
o setor menos competitivo e desincentivando o investimento. Segundo Oreiro e Feijó (2010), a apreciação cambial no período 2004-2008 foi acompanhada pela perda de dinamismo da indústria de transformação com respeito ao restante da economia brasileira. Ainda segundo os autores, entre 2005 e 2008 a taxa de crescimento do valor adicionado da indústria de transformação ficou sistematicamente abaixo da taxa de crescimento do PIB. Todo movimento foi acompanhado por uma forte apreciação do câmbio real.

O resultado desse processo pode ser visto em 2012, quando apesar do surgimento de uma tendência a desvalorização cambial, o déficit do setor industrial permanece aumentando, sendo influenciado principalmente pelos setores de média-alta e alta intensidade tecnológica. Tudo indica que este resultado negativo nada mais é que o reflexo da perda de dinamismo apresentada pelo setor industrial brasileiro nos últimos anos e da eliminação da certas cadeias de produtores nacionais.

\section{Conclusão}

Assim como vimos nas seções inicias do trabalho, a ideia de que o Brasil está em processo de desindustrialização está relacionada à perda de participação tanto do valor adicionado da indústria no PIB quanto do emprego industrial no emprego total. Observamos que a perda de participação do emprego industrial no emprego total é o ponto que leva os economistas a divergirem. Neste ponto, apresentamos a hipótese de que o peso do emprego industrial no emprego total pode ter permanecido constante (ou seja, não decresceu) simplesmente devido à queda de participação do total de ocupações no setor agropecuário, fato este proveniente do processo de mecanização do setor. De qualquer forma, este debate sobre o processo de desindustrialização do Brasil está longe de apresentar um consenso entre os economistas.

O presente trabalho buscou, dentro do debate sobre o processo de desindustrialização no Brasil, apresentar o panorama atual do setor externo brasileiro. Independentemente da discussão da existência ou não do processo de desindustrialização no Brasil, o trabalho mostrou a grande perda de participação dos produtos industriais na composição das exportações brasileiras, com destaque para os produtos de alta e média-alta intensidade tecnológica. Desta forma, o trabalho se identifica com a ideia de inserção regressiva apresentada por Gonçalves (2001), uma vez que constatamos a perda de competitividade internacional da indústria nacional e o fenômeno da reprimarização da pauta de exportação brasileira. 
Por fim, devemos ter em mente que a diferença entre os desempenhos econômicos dos países refletem, em grande medida, as interações existentes entre instituições governamentais e privadas que configuram o Sistema Nacional de Inovação ${ }^{11}$, bem como os diversos mecanismos de coordenação existentes. Dessa forma, sendo as políticas macroeconômicas (monetária, fiscal e cambial) parte integrantes do Sistema Nacional de Inovação, é necessário que haja uma coordenação entre seus principais objetivos e aqueles apresentados e relacionados às políticas industriais e tecnológicas. Portanto, além da adoção de uma Política Industrial e de Ciência e Tecnologia (C\&T) explicita, para que o Brasil gere novas tecnologias e contorne os processos de perda de participação da indústria no PIB e dos produtos industriais tecnologicamente sofisticados nas exportações, é necessário que seja adotada pelo governo brasileiro uma política macroeconômica condizente com os objetivos apresentados pela política industrial e tecnológica.

\section{Referências}

ALMEIDA, M. A. S.; SOUZA, G. F. de. Perfil exportador brasileiro entre 2000 e 2009: o Brasil versus China. Revista Economia Ensaios, Uberlândia (MG), v. 28, n. 1, p.7-26, Jul/Dez. 2013.

BELLUZZO, L. G.; ALMEIDA, J. G. Depois da queda: a economia brasileira da crise da dívida aos impasses do Real. Rio de Janeiro: Civilização Brasileira, 2002.

BRESSER-PEREIRA, L. C. Doença holandesa e sua neutralização: uma abordagem ricardiana. Doença holandesa e a indústria. Revista de Economia Política, v. 28, n. 1, p. 47 $71,2008$.

BUAINAIN, A. M.; DEDECCA, C. S. Introdução: Emprego e Trabalho na Agricultura Brasileira. MIRANDA, C.; TIBÚRCIO, B. (Org.). Emprego e Trabalho na Agricultura Brasileira. Brasília: IICA, nov. 2008, p. 19-61. Série Desenvolvimento Rural Sustentável, v. 9. Disponível em:

<http://www.iica.int/Esp/regiones/sur/brasil/Lists/Publicacoes/Attachments/32/Serie\%20DRS $\% 20 \mathrm{vol} \% 209 \% 20-$ \%20Emprego\%20e \%20Trabalho\%20na\%20Agricultura\%20Brasileira.pdf > . Acesso em 23 jul. 2013.

CAVALCANTI, M.; RIBEIRO, F. As exportações brasileiras no período 1977/96:Desempenho e determinantes. IPEA, Texto para Discussão n. 545. Rio de Janeiro,

\footnotetext{
11 Segundo o manual de Oslo (OCDE, 1996), o Sistema Nacional de Inovação pode ser definido como um conjunto de organizações e instituições responsáveis pela criação e adoção de inovações em um determinado país. As políticas nacionais enfatizam as interações entre as instituições que participam do processo de criação, difusão e aplicação do conhecimento. Podemos dizer que a ideia básica do conceito de sistemas de inovação é que o desempenho inovativo depende não apenas da performance das empresas e organizações de ensino e pesquisa, mas também da forma como elas interagem entre si e com os vários outros atores, e como as instituições (inclusive políticas) afetam o desenvolvimento dos sistemas inovativos.
} 
1998. Disponível em: 〈 https://ipea.gov.br/agencia/images/stories/PDFs/TDs/td_0545.pdf $>$. Acesso em: 17 de julho de 2013.

DELGADO, P. R. Evolução e perfil do emprego no setor sucroalcooleiro paranaense. Caderno IPARDES (Instituto Parananense de Desenvolvimento Econômico e Social). Curitiba, PR, v.2, n.1, p. 44-57, jan/jun. 2012.

GONÇALVES, R. Competitividade Internacional e Integração Regional: A Hipótese da Inserção Regressiva. Revista de Economia Contemporânea. 5ª Ed. Rio de Janeiro, 2001.

IPEA (Instituto de Pesquisa Econômica Aplicada). (2012). Produtividade no Brasil nos anos 2000-2009: análise das contas nacionais. Brasília: Ipea, 3 fev. 2012. (Comunicado da Presidência, n. 133).

OCDE (Organização para a Cooperação e Desenvolvimento Econômico). Manual de Oslo: OECD proposed guildelines for collecting and interpreting technological innovation data. Paris, 1996. Disponível em: < http://www.oecd.org/sti/inno/2367580.pdf >. Acesso em: 28 de julho de 2013.

OREIRO, J.L.; FEIJÓ, C. Desindustrialização: conceituação, causas, efeitos e o caso brasileiro. Revista de Economia Política, v. 30, n. 2, p. 219-232, abril-junho, 2010.

PALMA, G. Quatro fontes de desindustrialização e um novo conceito de doença holandesa. Conferência de Industrialização, Desindustrialização e Desenvolvimento, Federação das Indústrias do Estado de São Paulo (FIESP), 2005.

ROWTHORN, R.; RAMASWANY, R. Growth, Trade and Deindustrialization. IMF Staff Papers, Vol. 46, N.1, 1999.

SQUEFF, G. C. Desindustrialização: luzes e sombras no debate brasileiro. IPEA, Texto para Discussão 1747, 2012.

TREGENNA, F. Characterizing deindustrialization: an analysis of changes in manufacturing employment and output internationally. Cambridge Journal of Economics, Vol. 33, 2009.

WASQUES, R. N. O fenômeno da desindustrialização: uma análise do caso brasileiro na década de 2000. Revista Economia Ensaios, Uberlândia (MG), v. 26, n. 1, p.65-84, Jul/Dez. 2011.

Recebido em 25.06.14

Aprovado em 19.02.15 